\title{
CAN WE PROMOTE WALKING AS URBAN TRANSPORT?
}

\author{
SUZANNE AUDREY \& HARRIET FISHER \\ Population Health Sciences, Bristol Medical School, University of Bristol, United Kingdom
}

\begin{abstract}
Our research examined the acceptability and effectiveness of a Walk to Work programme in urban workplaces. We conducted a feasibility study and a full-scale randomised controlled trial focusing on the context, implementation and response to an intervention to promote walking during the commute. The 10-week intervention involved training workplace-based Walk to Work promoters to encourage colleagues to increase walking during the journey to and from work. Interviews were conducted with a sample of employers, Walk to Work promoters and employees. During the feasibility study a range of employer perspectives were identified, from active support through uncertainty and cynicism, to resistance. In the main trial, 654 employees from 87 workplaces in south-west England and south Wales provided information about their commute through wearing accelerometers and Global Positioning System (GPS) receivers and completing travel diaries and questionnaires. In comparison to car users, walkers accrued substantially higher levels of daily Moderate to Vigorous Physical Activity (MVPA) during the commute $(34.3 \pm 18.6$ vs. $7.4 \pm 7.6$ minutes, $p<0.001)$ and throughout the day $(71.4 \pm 21.3$ vs. $45.7 \pm 20.9$ minutes, $p<0.001)$. There was strong evidence that walking to work was associated with a commute distance of less than two kilometres $(\mathrm{p}<0.001)$ and the absence of free work car parking $(\mathrm{p}<0.01)$. We conclude that walking to work could be an important contributor to urban transport and physical activity levels for working adults. However, attempts to increase walking as urban transport need to take account of individual and workplace circumstances, and wider transport policies. This includes commuting distances, availability of car parking and perceptions of commuting routes. Supporting walking during the daily commute should be a priority for transport, urban planning and public health disciplines.
\end{abstract}

Keywords: walking, commuting, active travel, physical activity, workplace, behavioural intervention.

\section{INTRODUCTION}

Active travel is of interest to researchers, policy makers and practitioners in several disciplines including public health, transport, urban planning and the environment. From a public health perspective, it is known that regular physical activity reduces the risk of developing chronic diseases such as type 2 diabetes, cardiovascular disease and some cancers [1]. The current recommendation is that adults should undertake 150 minutes or more of moderate intensity physical activity throughout the week in bouts of at least 10 minutes [1][3] However, within the context of increasingly sedentary lifestyles, many adults in higher income countries do not achieve this relatively modest recommendation [4]. In the United Kingdom (UK), one study found $41 \%$ of adults aged between 40 and 60 years reported that there were no occasions during the month when they walked continuously for ten minutes a brisk pace [5]. Consequently, increasing physical activity levels, particularly among the most inactive, is an important aim of current public health policy in the UK and other higher income countries.

For working adults, the daily commute may offer an important opportunity to incorporate the recommended activity levels within their daily routine. Systematic review evidence suggests that adult populations who commute using active modes of transport, such as walking and cycling, achieve overall higher levels of physical activity than those who commute by car [6]-[8]. Furthermore, a cost benefit analysis of active transport undertaken in the UK suggested the active transport is a good investment as the benefits substantially outweigh costs incurred [9]. 
Although walking and cycling are frequently combined in the general term "active travel", they are quite different activities and are likely to appeal to different population groups [10]. For many people walking is a more familiar activity than cycling, that does not require the purchase of special equipment and is less likely to involve sharing road space with motorised traffic. For those who are the least physically active, walking may be seen as a safer, easier and cheaper introduction to active travel.

Walking is a carbon neutral mode of transport that has declined as car use has increased. Despite problems with traffic congestion and air quality in many towns and cities, even short journeys may be undertaken by car. For example, in the UK the 2016 National Travel Survey showed $24.5 \%$ of car journeys were shorter than $3.2 \mathrm{~km}$ ( 2 miles), and $13 \%$ of trips less than $1.6 \mathrm{~km}$ (1 mile) were undertaken in a car [11].

Although there are compelling reasons to encourage people to walk more, walking tends to be neglected by travel planners and greater emphasis is placed on the movement (and parking) of motorized vehicles, public transport provision, and cycling as active travel. In contrast, our research has focused specifically on walking as part of the daily commute.

\section{METHODS}

\subsection{Development and feasibility work}

A feasibility study was conducted in the south-west of England between October 2011 and December 2013 with the aim of building on the available existing resources and knowledge to develop a workplace scheme to increase walking during the commute, and to examine the feasibility of implementing and evaluating it in a full-scale randomized controlled trial [12]. A review of current resources promoting walking, and especially those focussing on the benefits of walking to work, was undertaken. Three focus groups were undertaken with employees, and interviews conducted with three employers in workplaces of different sizes to finalise the intervention design. This development phase was followed by an exploratory randomised trial in 17 workplaces with 187 participating employees. An integral process evaluation included post intervention interviews with employers and employees to examine the context, delivery and receipt of the intervention and explore their views about walk to work initiatives. The feasibility study enabled the research team to develop and refine the Walk to Work intervention, as well as showing that it was feasible to recruit workplaces and employees and to implement and evaluate the intervention. This led to a successful application to undertake a full-scale randomised controlled trial in 87 workplaces (44 in the intervention arm, and 43 control) across seven urban areas in the south-west of England and south Wales between November 2014 and October 2017 [13]. To objectively examine physical activity levels and mode of travel, participating employees were asked to wear accelerometers and GPS monitors, and to complete questionnaires and travel diaries, at baseline and at 12-month follow up.

\subsection{The Walk to Work intervention}

Workplaces in the intervention arm were asked to identify a Walk to Work promoter who could be a volunteer with an interest in the study or an employee nominated by their employer because of their suitability for the role. In some cases, employers took on the role themselves. The Walk to Work promoters received training, provided by the research team, in their workplace. The Walk to Work intervention was based on nine key behavioural change techniques: intention formation, instruction, barrier identification, goal setting, general 
encouragement, self- monitoring, social support, review of goals and relapse prevention [14], [15]. The training session included information about the benefits of walking and guidance about how to use behavioural change techniques and access websites and resources for additional information. The training was summarised in a DVD which promoters retained after the session. Walk to Work promoters were also given booklets, which were discussed in detail during the training session, providing guidance about how to perform their role.

The role of the Walk to Work promoter was to distribute Walk to Work booklets and an optional pedometer to participating employees, discuss with them the benefits of increased walking, help employees consider how they might overcome barriers to walking during the commute, and provide on-going support over the following 10-week period. This support was through four contacts which could be face-to-face, by telephone or email depending on the circumstances of the participants and the workplace. The Walk to Work promoters were encouraged in their role through three short newsletters provided by the research team over the 10 -week intervention period. The promoters were also asked to circulate the newsletters to participating employees to help maintain interest and participation in the intervention.

Employers were also provided with a pack to encourage them to take an interest in the intervention and support the Walk to Work promoters and participating employees. The pack included information about the intervention, copies of the booklets for Walk to Work promoters and participants, poster templates which could be adapted for display in individual workplaces, and an additional employer's booklet with ideas about how to promote walking to work. These ideas included improving cloakroom facilities, providing lockers, giving information about walking distances, offering free incentive items for those who switch to walking e.g. rucksacks or breakfast vouchers, and supporting workplace competitions those who enjoy taking part in such activities.

\subsection{Data collection and analysis}

Our work has entailed collecting both qualitative and quantitative data. In this paper we focus on qualitative findings from the feasibility study relating to employers' views of promoting walking during the commute [16], and quantitative data relating to physical activity and factors associated with walking during the commute [17]. Together these data identify some of the key issues influencing whether we can promote walking as urban transport.

\subsubsection{Qualitative data collection and analysis}

Interviews were conducted with employers purposively chosen to represent different sized workplaces (9 small: $<50$ employees; 11 medium-sized: 20-249; 6 large: $\geq 250$ ) in different locations (14 city centre; 12 suburban). Employers or managers were asked to give their views about active travel and schemes to encourage walking to work, to describe the context of their workplaces and, for those in the intervention arm only, their opinions about the Walk to Work intervention.

Interviews were conducted in 26 workplaces with 29 employers/managers, 18 of whom were female. Five interviews were conducted during the intervention development phase, 12 during the feasibility trial before randomization, and seven in intervention workplaces after the 10 -week intervention period. A further six interviews were conducted with a random sample of employers who initially expressed an interest but did not go on to take part in the study. The average length of interview was 25 minutes (ranging between 11 and 77 minutes). All interviews were digitally recorded, fully transcribed and analysed using the Framework approach [18], [19]. The transcripts were read and sections of text relating to specific research questions (for example, the feasibility of implementing workplace schemes to promote 
walking to work) were extracted and inserted in charts for further scrutiny. Streamlined versions of the charts were produced by retaining key words and phrases whilst removing repetition and extraneous text. Key issues were identified, including similarities and differences within emerging themes.

\subsubsection{Quantitative data collection and analysis}

The data presented in this paper are baseline data across all workplaces before randomisation took place. These data were collected from 87 workplaces (45 small, 22 medium-sized and 20 large) located in urban areas in south-west England and south Wales. A total of 654 employees were recruited to the study in two phases (May-July 2015 and March-May 2016). A variety of workplaces were recruited including public administration, services and manufacturing, retail and professional and scientific organisations. Employees who consented to take part in the study were asked to wear accelerometers (Actigraph GT3X+) during waking hours for seven days, to carry or wear a personal GPS receiver (QStarz BT1000XT) during their commute and to complete travel diaries [17]. Participants were also asked to complete questionnaires which included questions about their sociodemographic characteristics, and perceptions of journeys to work.

Raw accelerometer data were downloaded and summarised over 10-second epochs using Actilife software (v6.11.8, ActiGraph LLC) and further processed using KineSoft (v3.3.80; KineSoft, Saskatchewan, Canada) software to generate outcome variables.

GPS and accelerometer data were combined for every 10-second epoch (accGPS) based on the Actigraph data timestamp. Participants' workplaces and homes were geocoded using postcodes and imported into a Geographical Information System (GIS) (ArcMap v10.2.2) with the merged accGPS files, which enabled the visual identification of participants journeys to and from work. Mode of travel was derived through visual analysis using several variables: GIS location for each epoch; sustained counts per 10-second epoch $<17$ for bus, train or car; and $>325$ for walking and cycling [20]; changes to sum of signal to noise ratio using a drop to $<250$ to indicate movement from indoor to outdoor environment [21], and; maximum speeds for walking as $\leq 10 \mathrm{~km} / \mathrm{hr}$, cycling $\leq 40 \mathrm{~km} / \mathrm{hr}$, bus $10-50 \mathrm{~km} / \mathrm{hr}$, and train or car $>50 \mathrm{~km} / \mathrm{hr}$ [22]. In line with another study [23], we defined participants as "inactive" or "active" during the commute if their mean MVPA accrued during the daily commute was less or more than ten minutes. Participants were required to provide accelerometer data for at least three days of at least 600 minutes duration to be included in analyses of daily physical activity, and at least one valid working day of accGPS data for mode and physical activity during the commute.

\section{EMPLOYERS VIEWS OF PROMOTING WALKING TO WORK}

\subsection{Advantages and disadvantages to employers}

Employers described several advantages if more of their employees walked to work [16]. These included a healthier workforce, which could also lead to reduced absenteeism and increased productivity. In terms of corporate responsibility, some workplaces felt they should be seen to be promoting healthier lifestyles, considering the environment and reducing their carbon footprint. In urban areas where traffic congestion was a problem, it was suggested that staff who walked had a predictable journey time which could lead to better timekeeping and less stress during the commute. In many workplaces, car parking was a contentious issue. Providing free car parking could be expensive for employers and, if there was limited availability, could lead to competition for parking spaces amongst employees. Furthermore, 
providing parking for employees could lead to fewer parking spaces for customers and clients of the business.

While the advantages of encouraging more employees to walk to work were recognised, employers also identified some disadvantages. Inclement weather could mean employees required more space to store and hang clothes, and improved cloakroom facilities, which could be a problem for small businesses. In some workplaces, employees required a vehicle to do their work to carry heavy equipment or travel to several different venues during the working day. Employers felt they should not advocate a change of travel mode that might lead to problems for their employees, for example, if employees worked unsocial hours, or the journey to work involved crossing busy roads or passing through areas that were considered unsafe.

\subsection{Resistance}

Some employers did not want to promote change of travel mode amongst their employees because they felt it was their role to do so, rather employees should be able to make their own arrangements without feeling that their employer was putting pressure on them to choose a particular travel mode. Transitions, such as relocation or reorganisation of workplaces, offer opportunities to review travel arrangements. However, in one large workplaces that declined to take part in the study, the employer stated that their imminent relocation was already upsetting employees and it would be insensitive to suggest employees also change their travel mode.

Some employers were against workplace-based health promotion, suggesting that people might wish to engage in initiatives in their own time, but it was not the responsibility of the workplace. In other workplaces it was suggested that there was insufficient time to engage in activities that were not central to the business. In the case of the Walk to Work intervention, a member of staff was required to take time out to be trained and promote walking amongst other employees. Where budgets and timetables were tight, this was seen as compromising the main activities of the workplace.

\subsection{Cynicism}

The lack of progress in relation to previous workplace travel plans and sustainable transport left some employers sceptical about the likelihood of success in changing employees travel behaviour. Some suggested a backlash from people who were fed up with being preached at, and there was some evidence of stereotyping employees as not being the sort of people who cared about such initiatives. It was felt that there is sufficient information and guidance in the public domain and yet people choose to ignore it.

\subsection{Uncertainty}

Some employers were willing to promote walking during the commute but uncertain about whether it could be achieved. This was especially evident where there was plentiful car parking and driving was perceived as an easy option amongst employees.

Walking may not be perceived as transport, but rather something that we all which does not require any special equipment or training. This can lead to uncertainty about how to actually "promote" walking, in contrast with schemes to promote cycling in which bicycle racks may be provided, cycle training organised, or grants made available to purchase bicycles. If walking was to be promoted, there was uncertainty about whether employees 
would want to engage with a workplace Walk to Work promoter or whether such an initiative would be better provided by an external organisation.

\subsection{Support}

Despite some resistance, cynicism and uncertainty there were also employers who were keen to support walking to work. Although these tended to be organisations with a strong commitment to be a responsible employer, there were other motivations. The lack of parking, or the need to implement parking restrictions, led some employers to seek ways of encouraging employees to make alternative travel arrangements. However, restrictions on parking can be a cause of tension between employer and employee and some employers felt it was better if such restrictions were implemented at policy level by local or national government. If such restrictions are implemented by workplaces, there may be less tension between in the workplace if the policy was implemented by a more distant "head office" than by a local manager.

Some employers identified situations in which they may be able to promote walking during the commute, including when recruiting new staff or relocating to new premises. Others suggested ways in which they could support walking including allowing flexible working hours, providing breakfast for walkers and supporting workplace competitions.

\section{PHYSICAL ACTIVITY DURING THE COMMUTE}

Here we compare the participants who walked to work with those who made the journey by car. Table 1 shows that a substantially higher proportion of walkers $(24,38.7 \%)$ achieved the recommended levels of physical activity compared with car users $(17,4.8 \%)(p<0.001)$. There were marked differences in time spent in MVPA by main mode of travel (Table 1). Overall, walkers (71.3 minutes, $\mathrm{SD} \pm 21.3)$ accumulated more MVPA throughout the day in comparison to car users (46.3 minutes, $\mathrm{SD} \pm 20.6$ ). Walkers (34.3 minutes, $\mathrm{SD} \pm 18.6$ minutes) were also on average more active during the commute than car users (7.3 minutes, $\mathrm{SD} \pm 7.6)$.

Table 1: Physical activity and travel mode. (Source: Batista Ferrer et al. 2018.)

\begin{tabular}{|l|l|l|l|}
\hline \multirow{2}{*}{ Category } & Car (n=357) & Walks (n=62) & \multirow{2}{*}{ p-value* } \\
\cline { 2 - 4 } & $\mathbf{n}(\mathbf{\%})$ & $\mathbf{n}(\mathbf{\%})$ & \\
\hline $\begin{array}{l}\text { Meets public health physical activity } \\
\text { guidelines** }\end{array}$ & $17(4.8)$ & $24(38.7)$ & $<0.001$ \\
\hline & Mean (SD) & Mean (SD) & p-value $\dagger$ \\
\hline $\begin{array}{l}\text { Overall daily physical activity (counts per } \\
\text { minute) }\end{array}$ & $342.7(120.1)$ & $507.2(151.2)$ & $<0.001$ \\
\hline Mean daily MVPA (minutes) & $46.3(20.6)$ & $71.3(21.3)$ & $<0.001$ \\
\hline & $\mathbf{N}=\mathbf{4 0 4}$ & $\mathbf{N}=71$ & \\
\hline Mean daily commute time (minutes) & $86.6(51.0)$ & $53.8(29.2)$ & $<0.001$ \\
\hline $\begin{array}{l}\text { Mean daily time spent in MVPA during } \\
\text { commute (minutes) }\end{array}$ & 7.3 (7.6) & $34.3(18.6)$ & $<0.001$ \\
\hline $\begin{array}{l}\text { SD: Standard Deviation; MVPA: Moderate to Vigorous Physical Activity } \\
\text { * Derived from chi-squared test; } \dagger \text { Derived from ttest statistics } \\
\text { ** For adults: 150 minutes accumulated during the week in bouts of at least 10 minutes }\end{array}$ \\
\hline
\end{tabular}


Table 2: Predictors of physical activity during commute. (Source: Batista Ferrer et al. 2018.)

\begin{tabular}{|c|c|c|c|c|c|c|}
\hline \multirow{3}{*}{ Category } & Inactive & Active & \multirow{3}{*}{$\begin{array}{c}\text { OR } \\
\text { (95\% CIs) }\end{array}$} & \multirow{3}{*}{$\begin{array}{c}\text { p- } \\
\text { value }\end{array}$} & \multirow{3}{*}{$\begin{array}{c}\text { aOR } \\
(95 \% \\
\text { CIs) }\end{array}$} & \multirow{3}{*}{$\begin{array}{c}\text { p- } \\
\text { value }\end{array}$} \\
\hline & $\mathrm{N}=349$ & $\mathrm{~N}=\mathbf{2 4 8}$ & & & & \\
\hline & n (\%) & n (\%) & & & & \\
\hline $\begin{array}{l}\text { Overweight or } \\
\text { obese }\end{array}$ & $\begin{array}{c}179 \\
(64.2)\end{array}$ & $\begin{array}{c}100 \\
(35.8)\end{array}$ & - & & - & \\
\hline $\begin{array}{c}\text { Underweight or } \\
\text { normal }\end{array}$ & $\begin{array}{c}143 \\
(54.0)\end{array}$ & $\begin{array}{c}122 \\
(46.0)\end{array}$ & $\begin{array}{c}1.53 \\
(1.08-2.15)\end{array}$ & 0.02 & \begin{tabular}{|c|}
1.48 \\
$(1.04-$ \\
$2.12)$
\end{tabular} & 0.03 \\
\hline $\begin{array}{l}\text { Non-sedentary } \\
\text { occupation }\end{array}$ & $87(69.1)$ & $\begin{array}{c}39 \\
(31.0)\end{array}$ & - & & - & \\
\hline $\begin{array}{l}\text { Sedentary } \\
\text { occupation }\end{array}$ & $\begin{array}{c}229 \\
(55.5)\end{array}$ & $\begin{array}{c}184 \\
(44.6)\end{array}$ & $\begin{array}{c}1.79 \\
(1.17-2.74)\end{array}$ & $<0.01$ & \begin{tabular}{|c|}
1.96 \\
$(1.26-$ \\
$3.04)$
\end{tabular} & $<0.01$ \\
\hline $\begin{array}{c}\text { Commute distance } \\
>4 \mathrm{~km}\end{array}$ & $\begin{array}{c}276 \\
(64.9)\end{array}$ & $\begin{array}{c}149 \\
(35.1)\end{array}$ & - & & - & \\
\hline $\begin{array}{c}\text { Commute distance } \\
2-4 \mathrm{~km}\end{array}$ & $36(40.9)$ & $\begin{array}{c}52 \\
(59.1)\end{array}$ & $\begin{array}{c}2.68 \\
(1.67-4.28)\end{array}$ & $<0.001$ & \begin{tabular}{|c|}
2.73 \\
$(1.69-$ \\
$4.41)$ \\
\end{tabular} & $<0.001$ \\
\hline $\begin{array}{l}\text { Commute distance } \\
<2 \mathrm{~km}\end{array}$ & $20(40.6)$ & $\begin{array}{c}38 \\
(59.4)\end{array}$ & $\begin{array}{c}2.71 \\
(1.58-4.63)\end{array}$ & $<0.001$ & \begin{tabular}{|c|}
2.74 \\
$(1.58-$ \\
$4.73)$
\end{tabular} & $<0.001$ \\
\hline $\begin{array}{l}\text { Inactive: Mean daily } \\
\text { Active: Mean daily } 1 \\
\text { aORs adjusted for w }\end{array}$ & $\begin{array}{l}\text { VPA du } \\
\text { PA duri }\end{array}$ & $\begin{array}{l}\text { comm } \\
\text { ommu }\end{array}$ & $\begin{array}{l}\text { 10 minutes } \\
\text { Ominutes }\end{array}$ & 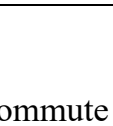 &  & \\
\hline
\end{tabular}

\section{FACTORS ASSOCIATED WITH WALKING TO WORK}

Valid accGPS data for at least one day was provided by 597 participants. After adjustment for weight status, occupational activity, and commute distance there was no evidence that gender, age, household income or educational achievement influenced physical activity levels during the commute. However, there was strong evidence that participants who lived shorter distances (up to $4 \mathrm{~km}$ ) from the workplace or had sedentary jobs were more physically active during their commute, and weaker evidence that not being overweight was also associated with more physical activity during the commute (Table 2).

Information about a range of personal, workplace and environmental factors were collected through the questionnaires completed by participants. Our analyses considered which of these factors were predictors of walking as the main mode of transport. There was no evidence to suggest that gender, age, household income or educational qualifications were associated with walking during the commute. After adjustment, there was strong evidence that not having access to a car was positively associated with walking to work (Table 3 ). A commute distance of up to $4 \mathrm{~km}$ was a strong predictor of walking to work, as was a lack of free parking at the workplace. However, there was no evidence that other workplace factors such as showers, storage or workplace travel plans influenced walking to work. 
Table 3: Predictors of walking as main mode of commute. (Source: Batista Ferrer et al. 2018.)

\begin{tabular}{|c|c|c|c|c|c|c|}
\hline \multirow{3}{*}{ Category } & \multirow{2}{*}{$\begin{array}{c}\begin{array}{c}\text { Car } \\
\text { users }\end{array} \\
\mathrm{N}=422\end{array}$} & \multicolumn{4}{|c|}{ Walkers } & \multirow[b]{3}{*}{$\begin{array}{l}\text { p- } \\
\text { value }\end{array}$} \\
\hline & & $\mathrm{N}=74$ & & & & \\
\hline & n $(\%)$ & n (\%) & $\begin{array}{l}\text { OR } \\
(95 \% \mathrm{CI})\end{array}$ & $\begin{array}{l}\text { p- } \\
\text { value }\end{array}$ & $\begin{array}{l}\text { aOR } \\
(95 \% \mathrm{CI})\end{array}$ & \\
\hline \multicolumn{7}{|l|}{ Personal } \\
\hline $\begin{array}{l}\text { Underweight or } \\
\text { normal }\end{array}$ & $\begin{array}{l}178 \\
(42.2) \\
\end{array}$ & $\begin{array}{l}44 \\
(59.5)\end{array}$ & $\begin{array}{l}2.31 \\
(1.34-3.97)\end{array}$ & $<0.01$ & NI & \\
\hline No access to car & $9(2.1)$ & $\begin{array}{l}21 \\
(28.4)\end{array}$ & $\begin{array}{l}20.4 \\
(8.78-47.2)\end{array}$ & $<0.001$ & $\begin{array}{l}20.5 \\
(6.01-69.8)\end{array}$ & $<0.001$ \\
\hline \multicolumn{7}{|l|}{ Workplace } \\
\hline Commute $2-4 \mathrm{~km}$ & $48(11.4)$ & $\begin{array}{l}21 \\
(28.4)\end{array}$ & $\begin{array}{l}11.3 \\
(5.30-24.0)\end{array}$ & $<0.001$ & $\begin{array}{l}15.0 \\
(5.55-40.6)\end{array}$ & $<0.001$ \\
\hline Commute $<2 \mathrm{~km}$ & $26(6.2)$ & $\begin{array}{l}35 \\
(47.3)\end{array}$ & $\begin{array}{l}34.7 \\
(16.4-73.5)\end{array}$ & $<0.001$ & $\begin{array}{l}63.6 \\
(21.5-187.9)\end{array}$ & $<0.001$ \\
\hline No free parking & $\begin{array}{l}147 \\
(34.8)\end{array}$ & $\begin{array}{l}38 \\
(51.4)\end{array}$ & $\begin{array}{l}3.02 \\
(1.69-5.40)\end{array}$ & $<0.001$ & $\begin{array}{l}3.19 \\
(1.38-7.39)\end{array}$ & $<0.01$ \\
\hline \multicolumn{7}{|l|}{ Environmental } \\
\hline $\begin{array}{l}\text { Positive } \\
\text { perception }\end{array}$ & $\begin{array}{l}161 \\
(38.2) \\
\end{array}$ & $\begin{array}{l}46 \\
(62.2) \\
\end{array}$ & $\begin{array}{l}3.44 \\
(1.95-6.10) \\
\end{array}$ & $<0.001$ & NI & \\
\hline
\end{tabular}

Univariable analyses suggested walkers had a more positive perception of their commute that car drivers, but this association was no longer evident after adjusting for other variables.

\section{DISCUSSION}

Our findings, supported by other related research, suggest that walking to work can have health benefits but the ability to change travel behaviour is influenced by factors at the personal, workplace and wider policy level.

\subsection{Potential health benefits}

Our work confirms low levels of physical activity in an adult working population in the UK. However, we found strong associations between physical activity and walking as the main mode of travel to work. Only $5 \%$ of car drivers met the physical activity recommendations, compared with $39 \%$ of walkers (Table 1). Active commuters were less likely to be overweight. These findings suggest that the daily commute offers an opportunity for working adults to incorporate physical activity into the daily routine and to reduce the risk of developing chronic diseases such as type 2 diabetes, heart disease and some cancers [1]. 


\subsection{Workplace relationships}

Because of the potential benefits of walking to work, it might be thought that the workplace is a suitable environment in which to encourage active modes of transport, and earlier studies have indicated the importance of senior management support if schemes to change travel behaviour are to succeed [24], [25]. However, employers in our study identified several issues which made them reluctant to take on the role. The study was conducted during an economic recession during which many employers conceded that the main business activities had to take priority in the workplace. Where downsizing or relocation were taking place, some employers felt it would be adding insult to injury by suggesting to their employees that they might try walking to work.

Although some employers felt promoting active travel would enhance the image of their workplace, and contribute to corporate responsibility, others feared that attempts to change travel mode might be interpreted as unwelcome interference in the lives of their employees outside of working hours. It appeared that employers were more comfortable promoting active travel and employees less suspicious of underlying motives if the workplace was already perceived as genuinely caring and supportive.

\subsection{Car parking}

We found a lack of free workplace car parking to be positively associated with walking to work. Other studies have linked lack on onsite car parking to reductions in car use and increased active travel [26]-[28], and the UK Department for Transport has argued that parking restrictions are the hallmark of high achieving travel plans [25]. However, our qualitative research suggests, where a measure to promote active travel may be interpreted as "punitive" (such as removing parking privileges), employers would prefer it to be perceived as being initiated from outside of the workplace, to reduce potential tension between employees and their employers. One way to mitigate the loss of parking could be compensatory payments for those who give up a parking space. An evidence synthesis examining financial incentives to support active travel concluded they may be a promising but underused method [29].

\subsection{Commuting distance}

We found walking to work to be positively associated with a shorter commuting distance. This supports the argument that more active modes of transport can be supported by local and national policies to provide and maintain employment opportunities close to residential areas [30]. Other studies in the UK have shown that a short distance to then workplace supports walking to work [23], [28], [31].

\subsection{Walking environment}

Although univariable analyses of our data suggested walkers had more positive perceptions of their commute environment than car users, but this association disappeared following adjustment for other variables. Factors, such as commute distance and availability of parking, were much more important for walking to work for our study participants. Other research has suggested some people will walk regardless of adverse environmental conditions, having considered the perceived benefits and costs [32]. However, other cross-sectional data found positive associations between walking and the built environment [33], [34]. In the UK, designated routes for walking and cycling have been linked with higher physical activity 
levels and active travel [35], [36], although distance from the routes was a mediating factor. This suggests that piecemeal, fragmented improvements to infrastructure may be insufficient to support behaviour change [37].

\section{CONCLUSION}

Walking is an important mode of active transport that can contribute to physical activity levels in the working population and improve public health. Interventions to increase walking to work should consider both personal and wider determinants of commuting behaviour, requiring the support of both transport and public health professionals.

\section{ACKNOWLEDGEMENTS}

We would like to thank all the workplaces and participants who contributed to the research, as well as our colleagues in the research team. This project was funded by the National Institute for Health Research Public Health Research (NIHR PHR) Programme (project number 10/3001/04). The views and opinions expressed therein are those of the authors and do not necessarily reflect those of the NIHR PHR Programme or the Department of Health. The work was undertaken with the support of The Centre for the Development and Evaluation of Complex Interventions for Public Health Improvement (DECIPHer), a UKCRC Public Health Research Centre of Excellence. Joint funding (MR/KO232331/1) from the British Heart Foundation, Cancer Research UK, Economic and Social Research Council, Medical Research Council, the Welsh Government and the Wellcome Trust, under the auspices of the UK Clinical Research Collaboration, is gratefully acknowledged.

\section{REFERENCES}

[1] Department of Health. Start active, stay Active: A report on physical activity for health from the four home countries, 2011.

[2] Haskell, W. et al., Physical activity and public health: Updated recommendation for adults from the American college of sports medicine and the American heart association. Circulation, 116(9), pp. 1081-1093, 2007.

DOI: 10.1161 /circulationaha.107.185649.

[3] World Health Organisation, Global recommendations on physical activity for health, 2010.

[4] Hallal, P., Andersen, L.B., Bull, F.C., Guthold, R., Haskell, W. \& Ekelund, U., Global physical activity levels: Surveillance progress, pitfalls, and prospects. The Lancet, 380(9838), pp. 247-257, 2012. DOI: 10.1016/s0140-6736(12)60646-1.

[5] Public Health England. 6 million adults do not do a monthly brisk 10-minute walk, 2017.

[6] Hamer, M. \& Chida, Y., Active commuting and cardiovascular risk: A meta-analytic review. Preventive Medicine, 46(1), pp. 9-13, 2008.

DOI: 10.1016/j.ypmed.2007.03.006.

[7] Saunders, L.E., Green, J.M., Petticrew, M.P., Steinbach, R. \& Roberts, H., What are the health benefits of active travel? A systematic review of trials and cohort studies. PLOS ONE, 8(8), pp. e69912, 2013. DOI: 10.1371/journal.pone.0069912.

[8] Kelly, P. et al., Systematic review and meta-analysis of reduction in all-cause mortality from walking and cycling and shape of dose response relationship. International Journal of Behavioral Nutrition and Physical Activity, 11(1), pp. 132, 2014.

DOI: 10.1186/s12966-014-0132-x. 
[9] Davis, A., Value for Money: An Economic Assessment of Investment in Walking and Cycling, DH: Bristol, 2010.

[10] National Institute for Health and Care Excellence, Physical activity: Walking and cycling, 2012.

[11] Department for Transport, National Travel Survey: England 2016, 2017.

[12] Audrey, S. et al., Employer schemes to encourage walking to work: feasibility study incorporating an exploratory randomised controlled trial. Public Health Research, 3(4), 2015. DOI: 10.3310/phr03040.

[13] Audrey, S. et al., Study protocol: The effectiveness and cost effectiveness of an employer-led intervention to increase walking during the daily commute: a cluster randomised controlled trial. BMC Public Health, 15(1), pp. 154, 2015.

[14] Michie, S. et al., The behavior change technique taxonomy (v1) of 93 hierarchically clustered techniques: Building an international consensus for the reporting of behavior change interventions. Annals of Behavioural Medicine, 46(1), pp. 81-95, 2013.

[15] Procter, S., Mutrie, N., Davis, A. \& Audrey, S., Participants' views of using behaviour change techniques to encourage walking to work. BMC Public Health, 14, pp. 868, 2014.

[16] Audrey, S. \& Procter, S., Employers' views of promoting walking to work: A qualitative study. International Journal of Behavioral Nutrition and Physical Activity, 12(1), p. 12, 2015. DOI: 10.1186/s12966-015-0174-8.

[17] Batista Ferrer, H., Cooper, A. \& Audrey, S., Associations of mode of travel to work with physical activity, and individual, interpersonal, organisational, and environmental characteristics. Journal of Transport \& Health, 9, pp. 45-55, 2018.

DOI: $10.1016 /$ j.jth.2018.01.009.

[18] Gale, N.K., Heath, G., Cameron, E., Rashid, S. \& Redwood, S., Using the framework method for the analysis of qualitative data in multi-disciplinary health research. $B M C$ Medical Research Methodology, 13(1), pp. 117, 2013. DOI: 10.1186/1471-2288-13117.

[19] Ritchie, J. \& Lewis, J., Qualitative Research Practice: A Guide for Social Science Students and Researchers, Sage: London, 2003.

[20] Freedson, P.S., Melanson, E. \& Sirard, J., Calibration of the computer science and applications, Inc. accelerometer. Medicine \& Science in Sports \& Exercise, 30(5), pp. 777-781, 1998. DOI: 10.1097/00005768-199805000-00021.

[21] Kerr, J., Norman, G., Godbole, S., Raab, F., Demchak, B. \& Patrick, K., Validating GPS data with the PALMS system to detect different active transportation modes. Medicine \& Science in Sports \& Exercise, 44, pp. S25-S29, 2012.

[22] Stopher, P., FitzGerald, C. \& Zhang, J., Search for a global positioning system device to measure person travel. Transportation Research Part C: Emerging Technologies, 16(3), pp. 350-369, 2008. DOI: 10.1016/j.trc.2007.10.002.

[23] Panter, J., Desousa, C. \& Ogilvie, D., Incorporating walking or cycling into car journeys to and from work: The role of individual, workplace and environmental characteristics. Preventive Medicine, 56(3), pp. 211-217, 2013.

DOI: 10.1016/j.ypmed.2013.01.014.

[24] Adams, E.J., Evaluation of Living Streets' "Walking Works Pathfinder Employers Scheme". BHF National Centre for Physical Activity and Health, Loughborough University, 2012.

[25] Newson, C., Making Travel Plans Work: Lessons from UK Case Studies, Department for Transport: London, 2002. 
[26] Cairns, S., Newson, C. \& Davis, A., Understanding successful workplace travel initiatives in the UK. Transportation Research Part A: Policy and Practice, 44(7), pp. 473-494, 2010. DOI: 10.1016/j.tra.2010.03.010.

[27] Panter, J., Jones, A., Van Sluijs, E.M.F., Griffin, S.J. \& Wareham, N.J., Environmental and psychological correlates of older adult's active commuting. Medicine \& Science in Sports \& Exercise, 43(7), pp. 1235-1243, 2011.

DOI: $10.1249 / \mathrm{mss} .0 \mathrm{~b} 013 \mathrm{e} 3182078532$.

[28] Dalton, A.M., Jones, A.P., Panter J.R. \& Ogilvie, D., Neighbourhood, route and workplace-related environmental characteristics predict adults' mode of travel to work. PLOS ONE, 8(6), p. e67575, 2013. DOI: 10.1371/journal.pone.0067575.

[29] Martin, A., Suhrcke, M. \& Ogilvie, A., Financial incentives to promote active travel. An evidence review and economic framework. American Journal of Preventive Medicine, 43(6), pp. e45-e57, 2012. DOI: 10.1016/j.amepre.2012.09.001.

[30] Department of Communities and Local Government, National planning policy framework, 2012.

[31] Panter, J., Griffin, S., Jones, A., Mackett, R. \& Ogilvie, D., Correlates of time spent walking and cycling to and from work: baseline results from the commuting and health in Cambridge study. International Journal of Behavioral Nutrition and Physical Activity, 8(1), p. 124, 2011. DOI: 10.1186/1479-5868-8-124.

[32] Guell, C., Panter, J. \& Ogilvie, D., Walking and cycling to work despite reporting an unsupportive environment: Insights from a mixed-method exploration of counterintuitive findings. BMC Public Health, 13(1), p. 497, 2013.

DOI: $10.1186 / 1471-2458-13-497$.

[33] Saelens, B. \& Handy, S., Built environment correlates of walking: A review. Medicine \& Science in Sports \& Exercise, 40(Suppl. 7), p. S550, 2008.

[34] McCormack, G. \& Shiell, A., In search of causality: a systematic review of the relationship between the built environment and physical activity among adults. International Journal of Behavioral Nutrition and Physical Activity, 8(1), p. 125, 2011. DOI: $10.1186 / 1479-5868-8-125$.

[35] Goodman, A., Sahlqvist, S. \& Ogilvie, D., New walking and cycling routes and increased physical activity: one- and 2-year findings from the UK iConnect Study. American Journal of Public Health, 104(9), pp. e38-e46, 2014.

DOI: 10.2105/ajph.2014.302059.

[36] Panter, J. \& Ogilvie, D., Can environmental improvement change the population distribution of walking? Journal of Epidemiology and Community Health, 71(6), pp. 528-535, 2017. DOI: 10.1136/jech-2016-208417.

[37] Song, Y., Preston, J. \& Ogilvie, D., New walking and cycling infrastructure and modal shift in the UK: A quasi-experimental panel study. Transportation Research Part A: Policy and Practice 95, pp. 320-333, 2017. DOI: 10.1016/j.tra.2016.11.017. 